\title{
PESQUISANDO SOBRE O DIREITO DA CONCORRÊNCIA
}

\section{RESEARCH TOPICS IN COMPETITION LAW}

RESUMO: O presente artigo pretende apresentar três grandes blocos de pesquisa para o estudante que pretende se aprofundar no Direito da Concorrência nos próximos anos. O primeiro bloco diz respeito à relação entre Política Industrial e Defesa da Concorrência, discussão que surgiu por conta da política de campeões nacionais, mas que fica mais densa a partir de uma comparação entre países desenvolvidos e em desenvolvimento. O segundo trata da relação entre políticas regulatórias e a defesa da concorrência, sobretudo por conta da adoção de várias medidas por parte das agências reguladoras com o objetivo de promover concorrência, sendo o maior exemplo as políticas de portabilidade. O terceiro e último bloco estimula o aluno a estudar a interação entre inovação e defesa da concorrência, de forma a avaliar se os instrumentos tradicionais utilizados em atos de concentração e condutas anticompetitivas se aplicam ou não a mercados caracterizados por alta tecnologia.

Palavras-Chave: Interações entre Políticas de Intervenção Estatal, Defesa da Concorrência, Política Industrial, Regulação, Inovação.

ABSTRACT: The present article intends to present three large blocks of research for the student who intends to deepen research in Competition Law in the coming years. The first block concerns the relationship between Industrial Policy and Antitrust, a discussion that arose recently because of the policy of national champions, but which is more dense based on a comparison between developed and developing countries. The second block deals with the relationship between regulatory policies and the Defense of Competition, especially as a result of the adoption of various measures by regulatory agencies with the aim of promoting competition, the most important

1 Professor Doutor da Escola de Direito da Fundação Getúlio Vargas - FGV DIREITO RIO. Membro Permanente do Mestrado em Direito da Regulação da FGV DIREITO RIO. Pós-Doutorando em Economia pela Universidade Federal Fluminense. E-mail: carlos.ragazzo@fgv.br. 
example being portability policies. The third and final block stimulates the student to study the interaction between innovation and defense of competition, in order to evaluate whether traditional instruments used in mergers and anticompetitive practice analysis apply or not to markets characterized by high technology.

KEYWORDS: Interactions among State Intervention Policies, Competition Law, Industrial Policy, Regulation, Innovation.

\section{INTRODUÇÃO}

O Direito da Concorrência, enquanto disciplina independente e autônoma, foi consagrado no Brasil após a edição da Lei 8884/94. Tal diploma normativo foi editado em meio às reformas econômicas e da Administração Pública da década de 90, que alteraram o paradigma da intervenção do Estado no domínio econômico e modificaram a própria dinâmica da economia brasileira. A liberalização dos mercados e a redução da intervenção direta do Estado criaram a necessidade de que outras formas de intervenção fossem pensadas e importadas. A preocupação com cartéis e oligopólios privados, menor em um contexto em que o Estado é o principal responsável pela produção de bens e serviços, passou para o centro dos debates, culminando com a edição da referida lei. As pesquisas sobre a livre concorrência tinham o desafio de aprimorar a prática e a teoria da defesa da concorrência no país e transpor debates estrangeiros sobre a melhor forma de tratar casos problemáticos do ponto de vista antitruste, como quando se aplica a regra da razão e a regra per $s e .^{2} \mathrm{~A}$ Lei 12529/11 foi o ponto nodal deste processo, aperfeiçoando o sistema brasileiro de defesa da concorrência e ajudando a alçá-lo ao grupo de liderança global na prática antitruste. $^{3}$

Porém, de um lado, as alterações nos paradigmas de intervenção do Estado no domínio econômico que deram origem a esse processo de mudança no papel da defesa da concorrência no Brasil também se alteraram. A tendência de contração da intervenção direta com a instituição de agências reguladoras se estabeleceu, mas, nos últimos anos, tem que conviver com uma nova forma de intervenção, marcado pelas práticas de fomento e pelas parcerias público-privadas. De outro lado, a própria dinâmica da economia está mudando, sendo cada vez mais relevantes as inovações tecnológicas disruptivas. O desafio de pesquisa, agora, é entender as consequências dos novos paradigmas de intervenção do estado e as inovações tecnológicas na teoria e na prática da defesa da concorrência.

2 Ver RAGAZZO, Carlos Emmanuel Joppert. A Regulação da Concorrência. In: Sérgio Guerra. (Org.). Regulação no Brasil: Uma Visão Multidisciplinar. 1ed. Rio de Janeiro: FGV, 2014, p. 157-188.

3 A autarquia recebeu ou foi finalista em diversas premiações internacionais prestigiadas, como o prêmio de Agência Antitruste das Américas em 2014 pela revista britânica Global Competition Review. 
A política industrial e de fomento dos governos brasileiros recentes trazem quais consequências ao papel do Direito da Concorrência? Os possíveis monopólios derivados das inovações tecnológicas devem ser tratados da mesma forma que os monopólios de setores tradicionais? Como é utilizada a livre concorrência em outras áreas do direito, e até que ponto isso se coaduna com objetivos do Direito da Concorrência? Essas perguntas mostram que as evoluções pelas quais passa o estudo do Direito da Concorrência tornam necessário que a pesquisa em torno da disciplina se adapte às múltiplas dimensões de utilização das ferramentas tradicionalmente consideradas. $\mathrm{O}$ estudo do Direito da Concorrência precisa estar em sintonia com o contexto em que é utilizado, e neste texto explorarei os principais caminhos da pesquisa na área, informados pelos desafios trazidos pelos contextos político, econômico e tecnológico recentes.

\section{AS NOVAS FRONTEIRAS DO DIREITO DA CONCORRÊNCIA}

Nesse contexto, percebe-se que o estudo do direito da concorrência não está, nem poderia estar, descasado das realidades e transformações jurídicas, econômicas, políticas e sociais. Todas essas disciplinas afetam a agenda de pesquisa do acadêmico do direito da concorrência, muitas vezes se entrelaçando e tornando a complexidade do estudo da matéria muito maior. Mudanças jurisprudenciais e doutrinárias no direito administrativo sancionador, por exemplo, têm um impacto direto no poder que o CADE exerce; teorias de responsabilidade civil precisam ser entendidas e associadas a questões econômicas por quem se debruça sobre a litigância em matéria concorrencial; a política industrial traçada por um governo pode gerar conflitos com concepções estabelecidas de defesa da concorrência; a disrupção tecnológica de indústrias também gera pressões pela alteração de paradigmas teóricos na matéria.

Daí surge uma enorme importância pedagógica no estudo, ensino e pesquisa do direito da concorrência. Tamanha interdisciplinaridade, que não se restringe à já estabelecida no Brasil Law \& Economics, produz uma infinidade de perspectivas para a pesquisa e o ensino. Estudar o direito da concorrência no século XXI, portanto, deve ser um exercício contínuo de evolução teórica, a fim de acompanhar as mudanças em outras disciplinas que possuem impactos diretos na defesa da concorrência. Nos últimos anos, a agenda de pesquisa se tornou extremamente variada, mas alguns temas parecem ter se posicionado no centro da agenda de pesquisa. Mais precisamente, venho acompanhando o desenvolvimento do direito da concorrência sob uma perspectiva de interações entre políticas de intervenções estatais. Tais políticas assumem diversas facetas, como a política de desenvolvimento industrial, a regulação econômica setorial e a criação de contornos para o desenvolvimento da "Nova Economia", pautada pela inovação tecnológica constante. É possível citar três perspectivas para o estudo do tema.

Primeiro, há a perspectiva do direito da concorrência como ferramenta de utilização do Estado para cumprir objetivos alheios à livre concorrência em si (instrumental). Essa visão se reflete na utilização dos instrumentos da defesa da concorrência com objetivos de promover políticas estatais, em especial, as políticas de desenvolvimento. Segundo, a defesa da concorrência enquanto forma de justificar 
intervenções pontuais do Estado no domínio econômico. Essas intervenções podem ocorrer de diversas formas, desde regras de proteção ao consumidor que devem ser aplicadas por juízes até normas reguladoras de setores específicos, como aquelas editadas pela ANATEL no setor de telecomunicações e pela ANS no setor de saúde suplementar (justificador da intervenção). Terceiro, é possível estudar a defesa da concorrência por meio do questionamento sobre como as novas tecnologias estão alterando os paradigmas teóricos tradicionais da disciplina: por exemplo, deveríamos tratar da mesma forma os monopólios causados por disrupções de novas indústrias e os das indústrias tradicionais?

Abaixo, discutirei brevemente esses três temas, mostrando como a pesquisa se desenvolveu nos últimos anos e como a agenda se estrutura para o futuro.

\section{DefeSA Da ConcorrênCIA E Desenvolvimento}

Nas últimas décadas, a pesquisa da defesa da concorrência tem se voltado para a sua utilização enquanto meio para promover políticas que tragam desenvolvimento econômico. Nesse contexto, as discussões sobre o papel do direito no desenvolvimento trouxeram duas consequências importantes para o direito da concorrência. Primeiro, há a discussão sobre a modificação do papel da defesa da concorrência na economia, com o surgimento de correntes que defendam cada vez mais o seu papel instrumental, e gera questionamentos sobre a necessidade de se adaptar o direito da concorrência a contextos de desenvolvimento distintos. A segunda consequência está numa necessidade de se repensar o papel tradicional do direito da concorrência em face das políticas de desenvolvimento, em especial a política industrial dos "campeões nacionais" promovida pelos últimos governos.

O direito da concorrência deveria partir das mesmas premissas em países desenvolvidos e em desenvolvimento? Essa é uma pergunta que foi pouco explorada na época de transplantação dos modelos europeu e americano aos países em desenvolvimento. Parecia óbvio que o modelo desenvolvido nos países centrais tinha uma racionalidade econômica fundamental que não dependia de contextos econômicos e sociais para ser válida. Procedeu-se, assim, na realização de importações de estruturas e normas jurídicas básicas com eventuais modificações para adaptação a contextos nacionais, mas com objetivos muitos semelhantes aos dos países de origem. ${ }^{4}$

\footnotetext{
${ }^{4}$ Eleanor Fox identificou quatro formas principais de importação de estruturas e normas de direito da concorrência pelos países em desenvolvimento: (i) começar pelo sistema americano, adotando um "antitruste mínimo" exceto nos casos de cartel; (ii) adoção dos princípios gerais que motivam o modelo antitruste norte-americano, com modificações nas regras e na interpretação de conceitos com o objetivo de ajustar o modelo à realidade desses países (poder-se-ia escolher a preferência por preços ao consumidor, por exemplo); (iii) adoção do modelo europeu, especialmente no que diz respeito à abertura e acesso e à suspeição para com ações estatais restritivas da concorrência; (iv) combinação de modelos de países em desenvolvimento que já desenvolveram uma direção no direito da concorrência, como a África do Sul. Ver FOX, Eleanor. Competition, Development and Regional Integration: In Search for a Competition Law Fit for Developing Countries. Law \& Economics Research Paper Series, working paper 11-04, NYU, 2012.
} 
No entanto, a literatura tem, desde a década passada, apontado que os desafios que devem ser enfrentados pela defesa da concorrência nos países em desenvolvimento são essencialmente diferentes. Dever-se-ia, apontam alguns autores, criar um sistema de defesa da concorrência com objetivos essencialmente distintos dos que são perseguidos nos países centrais: ao invés de somente objetivar a manutenção de preços em patamares competitivos e o alcance da eficiência, os países em desenvolvimento também deveriam se preocupar em utilizar o antitruste para construir uma ladeira de mobilidade social no longo prazo, incentivar o empreendedorismo e estimular inovações, além de se preocupar em tomar decisões capazes de aumentar desigualdades, ainda que haja eficiências. ${ }^{5}$ Nesses países, as altas barreiras à entrada se associariam à propriedade altamente concentrada e à governança corporativa duvidosa, fazendo com que o papel do antitruste precise ser repensado.

Nesse sentido, argumentam os autores dessa linha que o antitruste deveria passar cada vez mais de seu papel tradicional para atuar de forma justificadora e instrumental da intervenção estatal. Argumentos de promoção da livre concorrência seriam utilizados para "liberar as amarras" causadas por fatores sociais, políticos e históricos econômicos (papel justificador), de um lado, e as premissas da defesa da concorrência seriam modificadas para que as decisões facilitem a entrada pequenas empresas ou $\mathrm{o}$ foco em cartéis de produtos essenciais para o desenvolvimento humano. Ainda que haja bons argumentos econômicos para que o objetivo do direito da concorrência seja estrito, ${ }^{6}$ focando-se na eficiência alocativa, a pesquisa do direito da concorrência nos próximos anos precisa estar focada em verificar essas alegações e a entender melhor o papel que as decisões dos órgãos antitruste têm (ou que não têm) na manutenção ou na liberação das estruturas sociais, econômicas e políticas que emperram a mobilidade social nos países em desenvolvimento.

Dois fatores da política industrial brasileira das últimas décadas assumem relevância no que tange às interações com o direito concorrencial, constituindo importantes agendas de pesquisa: (i) os efeitos da política industrial dos "campeões nacionais" e (ii) o papel da política comercial.

O início da década de 2000 viu emergir no Brasil o que é chamado pela de literatura de Administração Pública de New State Activism (NSA). ${ }^{7}$ O governo Lula, buscando reconciliar parte das medidas neoliberais da década anterior com uma retomada do intervencionismo estatal, ${ }^{8}$ buscou alterar os mecanismos dessa intervenção. Passou-se a articular mais profundamente as ações estatais e privadas e criou-se uma política de

5 Ver FOX, Eleanor. Economic Development, Poverty and Antitrust: The Other Path. Southwestern Journal of Law and Trade in the Americas, v. 13, 2007 e DUTZ, Mark; KHEMANI, Shyam. Competition Law \& Policy: Challenges in South Asia. World Bank Report, 2007.

6 Ver, sobre isso, ELZINGA, Kenneth G. Goals of Antitrust: Other Than Competition and Efficiency, What Else Counts. U. Pa. L. Rev., v. 125, p. 1191, 1977, argumentando como os outros fins que se quer promover com o direito da concorrência são, no longo prazo, melhor promovidos com o foco na eficiência.

7 TRUBEK, David; COUTINHO, Diogo; SCHAPIRO, Mario. Towards a New Law and Development: New State Activism in Brazil and the Challenge for Legal Institutions. Univ. of Wisconsin Legal Studies Research Paper No. 1207, 2012.

8 BRESSER-PEREIRA, Luiz Carlos. From Old to New Developmentalism in Latin America. Textos para Discussão da Escola de Economia de São Paulo, vol. 193, 2009.

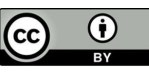


incentivo aos setores da economia brasileira que foram considerados estratégicos do ponto de vista do desenvolvimento. Foram privilegiados setores com a capacidade esperada de pôr o país na liderança internacional de produção e inovação, buscando criar e fortalecer líderes mundiais, e criou-se mecanismos com o objetivo de fortalecer indústrias fortes no mercado interno que ainda não eram players internacionais. ${ }^{9}$ Entre esses mecanismos, destacam-se os empréstimos subsidiados do BNDES para investimentos (especialmente internacionais), o incremento na participação estatal no quadro acionários de grandes empresas brasileiras, dando voz ao governo nas deliberações internas, e o compartilhamento de riscos de investimentos com o setor privado, com o objetivo de promover inovações.

Todos esses mecanismos decorrentes do novo modelo de intervenção do Estado na economia trouxeram desafios para as diferentes áreas do direito. ${ }^{10}$ Para o direito da concorrência, esses desafios são bastante evidentes ao se analisar uma das principais ferramentas do NSA: a política de incentivos às grandes fusões para a criação de "campeões nacionais" em alguns setores da economia. O BNDES financiou boa parte das grandes fusões em setores considerados estratégicos pelo governo, como as operações que deram origem à Brasil Foods, à OiBrT e à Ambev. ${ }^{11}$ A primeira análise, o papel tradicional do direito da concorrência é um freio a esse tipo de política, porque a própria lógica desse ramo do direito, da forma como foi implementado no Brasil, dá prevalência aos objetivos clássicos do direito da concorrência. ${ }^{12}$ Essa prevalência, que vem de uma escolha legislativa e da teoria econômica majoritária, foi expressa no seguinte trecho do meu voto na relatoria do caso da fusão entre a Sadia e a Perdigão:

Um ato de concentração que gere danos severos ao consumidor nacional não pode ser aprovado sob o mero argumento de que esse mesmo ato criou uma empresa forte, capaz de competir internacionalmente e exportar seus produtos. Não se trata de um mero capricho da Lei Antitruste. Trata-se, de modo bastante simples, e em acordo com os princípios jurídicos, econômicos e sociais mais básicos, de dar privilégio à coletividade e ao interesse público, em detrimento de se dar privilégio a um único agente econômico. ${ }^{13}$

A política industrial nacional também foi no sentido de fortalecer a prática do antidumping. Trata-se de uma prática que tem como objetivo a proteção do desenvolvimento da indústria nacional, e se entende que o antidumping é uma medida de aplicação rara, que deveria ser aplicada apenas àquelas situações em que a prática

\footnotetext{
9 TRUBEK, COUTINHO e SCHAPIRO (2009), op. cit., p. 10.

${ }^{10}$ Idem, p. 28 e ss.

11 ÉPOCA. “Os eleitos do BNDES”. Edição nํㅜ 631, de 18/06/2010, reportagem de capa.

12 Isso é exemplificado pelo artigo $54, \S 2^{\circ}$, da revogada lei 8884/94, que dispõe que argumentos de interesse público até podem ser levantados na defesa de uma fusão, mas somente se não houver prejuízo aos consumidores. Esse dispositivo não está presente na nova lei, potencialmente indicando o afastamento ainda maior do direito da concorrência de argumentos políticos.

${ }^{13}$ Ato de Concentração n⿳0 08012.004423/2009-18.
} 
de preços de exportação superiores aos preços dos mesmos produtos no mercado doméstico do país exportados esteja criando prejuízos à indústria nacional ou retardando o seu estabelecimento. ${ }^{14}$ A medida deveria ser excepcional segundo o papel tradicional da defesa da concorrência, porque o dumping se trata apenas de uma estratégia comercial que, via de regra, pode ter razões e consequências válidas, como (i) a entrada em novos mercados, (ii) a obtenção de economias de escala e (iii) a venda de estoques em excesso. O dumping predatório, com o objetivo de danificar a indústria nacional deve, portanto, ser atentamente provado.

A política industrial, no entanto, pode valorizar o antidumping como estratégia de garantir o desenvolvimento da indústria nacional. Se realmente houver dumping predatório ocorrendo em alguns setores, o fortalecimento das instituições responsáveis pela defesa comercial (no Brasil, DECOM e SECEX) pode permitir o melhor funcionamento do mercado. Nesse sentido, o NSA no Brasil adotou esse caminho. ${ }^{15}$ Quais as implicações disso para a pesquisa da defesa da concorrência? De novo, há que se analisar as interações entre seus diferentes papeis. No caso, enquanto o papel tradicional sugeriria uma política contida e limitada a algumas hipóteses, indícios apontam para um uso cada vez mais instrumental da defesa da concorrência: o antidumping como política protecionista. As indústrias tradicionalmente mais concentradas são as que concentram também os pedidos de medidas antidumping, e a emergência do NSA nos países em desenvolvimento coincidiu com o aumento exponencial das leis antidumping. ${ }^{16}$ Cabe às pesquisas futuras de defesa da concorrência analisar se a utilização do instituto no Brasil divergiu do seu papel tradicional para o instrumental.

Figura 1 - Produtos agrupados por setor

\begin{tabular}{lcccc}
\hline Setor & Com Aplicação & Sem Aplicação & Total & \% dos pedidos \\
\hline Siderurgia e Metalurgia & 41 & 21 & 62 & $22,50 \%$ \\
\hline Química & 35 & 25 & 60 & $22,10 \%$ \\
\hline Plásticos & 18 & 25 & 43 & $15,60 \%$ \\
\hline Têxtil, Madeira e Fibras & 21 & 7 & 28 & $10,10 \%$ \\
\hline Maq. Equip. e Transportes & 19 & 3 & 22 & $8 \%$ \\
\hline Borracha & 13 & 7 & 20 & $7,30 \%$ \\
\hline Outros Manufaturados & 11 & 6 & 17 & $6,20 \%$ \\
\hline Agronegócio & 15 & 2 & 17 & $\mathbf{6} \%$ \\
\hline Produtos Minerais & 2 & 4 & 6 & $\mathbf{1 0 0 \%}$ \\
\hline Total Geral & $\mathbf{1 7 5}$ & $\mathbf{1 0 0}$ & $\mathbf{2 7 5}$ & \\
* Produtos agrupados por setor de acordo com os 2 primeiros dígitos da NCM & &
\end{tabular}

Como ocorreu na década de 90, com a criação da lei que consagrou o sistema de defesa da concorrência no Brasil, as alterações nos paradigmas de intervenção do Estado no domínio econômico trazem a necessidade de se repensar o direito da

${ }_{14}$ MACERA, Andrea. A interação entre o antitruste e o antidumping: problema ou solução?. SEAE, documento de trabalho $\mathrm{n}^{\mathrm{0}} 36,2006$, p. 14.

15 TRUBEK, COUTINHO e SCHAPIRO (2009), op . cit., p. 31 e ss.

16 Ver dados em WOOTON, Ian; ZANARDI, Maurizio. “Trade and Competition Policy: Anti-Dumping versus Anti-Trust". University of Glasgow Working Papers 06, 2002. 
concorrência e seus papeis. Estamos possivelmente no fim do ciclo de intervenção estatal por meio do NSA, mas as polêmicas e choques com o sistema de defesa da livre concorrência trouxeram um debate acadêmico que veio para ficar. Isso mostra como os papeis da defesa da concorrência podem se chocar: no caso da política industrial brasileira de fortalecimento dos "campeões nacionais", o choque do papel instrumental com o papel tradicional ficou claro, enquanto no caso do antidumping, $\mathrm{O}$ papel tradicional foi repensado. Vai ficando claro, também, que os contextos políticos, econômicos e sociais podem ajudar a determinar o papel dominante que a defesa da concorrência terá.

\section{DEFESA DA CONCORRÊNCIA E REgulaÇÃo}

A regulação estatal de setores da economia passou por evoluções tanto em suas justificativas quanto em relação às variáveis que se escolhe regular. As regulações de preço e de entrada, que era a regra no início da regulação de serviços públicos, deram lugar ao aumento da complexidade na intervenção estatal, que passou a buscar a regulação das variáveis informação e qualidade. ${ }^{17}$ Essas novas estratégias regulatórias endereçam novos tipos de problema. Buscam corrigir as falhas de mercado por meio da liberalização de mercados e da promoção da concorrência, ao invés de se limitar a impor controles rígidos de preço e entrada, que podem trazer consequências de distorção econômica dos setores regulados. Por exemplo, medidas regulatórias buscam corrigir assimetrias ou melhorar fluxos informacionais para tornar viável a comparação pelos consumidores, levando eficiência a mercados que tradicionalmente são marcados por altos custos de transação. Isso é uma tendência em diversos setores, mas três casos de visibilidade podem ser notados aqui: serviços de telecomunicações e aviação civil.

O setor de telecomunicações voltado ao consumidor, especialmente a telefonia móvel e a internet banda larga, passou por uma grande alteração no seu perfil regulatório. $\mathrm{O}$ consumidor do setor sempre sofreu com problemas que impediam a troca de provedores do serviço, como (i) os custos de comparação entre as alternativas disponíveis, dada a quantidade de informações técnicas e variedade de pacotes, (ii) procedimentos de troca custosos, tanto por serem lentos e trabalhosos (incluindo os custos menos visíveis de mudança de número) quanto por incompatibilidades técnicas entre as operadoras (CDMA $v$ GSM, por exemplo). A autoridade reguladora do setor, ao invés de buscar regular as variáveis preço e entrada, como era no passado, vem editando normas capazes de reduzir esses custos e viabilizar a competição pelo consumidor ${ }^{18}$ Entre as medidas de sucesso que foram adotadas nos últimos anos está a portabilidade numérica, que reduziu os custos de troca do consumidor, justamente com o objetivo de trazer maior concorrência ao mercado. Outros setores passaram por movimentos semelhantes, como, por exemplo, o segmento de planos de saúde, que

17 Ver RAGAZZO, Carlos Emmanuel Joppert. Regulação Jurídica, Racionalidade Econômica e Saneamento Básico. Ed. Renovar: Rio de Janeiro, 2011.

18 Ver o Regulamento Geral de Direitos do Consumidor de Serviços de Telecomunicações (Resolução 632/14). 
também implementou medidas de portabilidade, dessa vez para períodos de carência, também para promover concorrência. Parece claro, portanto, que as medidas de concorrência, em setores regulados, não estão adstritas ao enforcement do CADE, mas sim estão sujeitas a um escopo mais amplo, em que o espaço de interlocução do órgão concorrencial com as agências reguladoras permite uma longa pauta de pesquisa para os próximos anos.

Esses casos demonstram que a defesa da concorrência, no Estado Regulador, passou a ter um forte papel justificador da intervenção do Estado em setores econômicos. Tal papel precisa ser estudado de forma que o sistema de defesa da concorrência seja tomado em interação com os outros papeis da defesa da concorrência, com o objetivo de dar coerência sistêmica às políticas de promoção da livre concorrência. Essa utilização do papel justificador pode ter impactos relevantes, por exemplo, no papel tradicional da livre concorrência, uma vez que fusões em setores regulados podem ser menos ou mais problemáticas de acordo com o contexto regulatório vigente.

\section{DEFESA DA CONCORRÊNCIA E INOVAÇÃO}

A última questão de pesquisa do direito da concorrência que será abordada aqui diz respeito à necessidade de se repensar o papel tradicional da defesa da concorrência devido às inovações tecnológicas e da "Nova Economia", que é caracterizada pela inovação constante, competição dinâmica pelo novo mercado, plataformas de vários lados, potenciais efeitos de rede e lock-in. ${ }^{19}$

Um dos principais casos que demonstram a dificuldade de lidar com os conceitos tradicionais do direito da concorrência na Nova Economia é o da Microsoft, envolvendo o seu navegador Internet Explorer. ${ }^{20}$ No caso, discutiu-se se a conduta da Microsoft de pré-instalar o seu navegador em seus sistemas operacionais era ou não anticompetitiva, visto que se alegava que o objetivo da Microsoft era neutralizar o crescimento do rival Netscape. O problema concorrencial estava relacionado a um conceito pouco discutido nos problemas tradicionais de defesa da concorrência: o chamado efeito de rede indireto. $\mathrm{O}$ efeito de rede direto ocorre quando o valor de participar na rede para cada usuário aumento quanto mais usuários a rede tiver. Já o efeito de rede indireto ocorre quando a rede tem mais de uma ponta, e o maior valor associado a uma dessas pontas aumenta o valor de estar na rede para os usuários da outra ponta. No caso, a ideia é que os usuários de determinado sistema operacional obtêm mais valor da utilização desse sistema se existirem muitos aplicativos para o mesmo; já os desenvolvedores de aplicativos obterão mais valor na criação de aplicativos para os sistemas operacionais que possuem a maior base de usuários. Daí se explica como a Microsoft alcançou 95\% do mercado, sendo um monopolista de difícil contestação no setor.

${ }^{19}$ Ver ECONNOMIDES, Nicholas. The Microsoft Antitrust Case. Journal of Industry, Competition and Trade: From Theory to Policy, edição de Agosto de 2001; e MANNE, Geoffrey; WRIGHT, Joshua. Innovation and the Limits of Antitrust. George Mason Law \& Economics Research Paper No. 09-54, 2009.

${ }^{20}$ United States v. Microsoft Corp., 253 F.3d 34, 55 (D.C. Cir. 2001). 
O problema surgiu com o potencial crescimento do desenvolvimento de aplicativos para o ambiente dos navegadores de internet. Com a possibilidade, os navegadores passaram a ser, potencialmente, objetos de efeito de rede indireto eles próprios, com mais usuários utilizando aqueles para os quais mais aplicativos são desenvolvidos e vice-versa. Isto é, passou-se a temer que os middlewares (como navegadores) substituíssem os sistemas operacionais como a rede de desenvolvimento de aplicativos. A consequência disso seria que os usuários não mais comprariam os sistemas operacionais pelas características de rede, mas sim por qualidade. Assim, vislumbrando a potencial ameaça ao seu monopólio, a Microsoft passou a entregar seu navegador pré-instalado e até mesmo impossibilitando a desinstalação do middleware, bem como dificultando a utilização de outros.

A primeira impressão é que se tratou de um caso de conduta exclusionária que poderia ser tratado pelos conceitos clássicos do direito da concorrência. Entretanto, as questões da livre concorrência na Nova Economia não são resolvidas de forma tão simples. As preocupações concorrenciais com a Microsoft, anos após a decisão do tribunal norte-americano, mostraram-se em descompasso com a realidade do mercado anos após, especialmente com a popularização de novas plataformas capazes de gerar efeitos de rede indiretos. A computação pessoal migrou cada vez mais para plataformas mais portáteis, como evidenciado pela evolução exponencial do market share da Apple com o iPad, que passou de menos de $10 \%$ para $25 \%$ do mercado de computadores pessoais menos de um ano após o lançamento do tablet, tendo o mercado de tablets superado o de PCs em 2015 (isso sem contar o crescimento posterior de plataformas como o Linux). ${ }^{21}$

Outro caso conhecido que torna questionáveis os paradigmas estabelecidos do papel tradicional da defesa da concorrência é o do Google. Monopolista no setor de buscas online, a empresa foi alvo, nos Estados Unidos e na Europa, de diversas ações e investigações concorrenciais. Manne e Wright ${ }^{22}$ mostram como é complexo transpor análises tradicionais do direito da concorrência para a Nova Economia a partir do caso Google. Em primeiro lugar, apontam que, por se tratarem de mercados novos, a definição do mercado relevante é muito difícil, costumando-se definir o mercado apenas com base em anedotas. Por exemplo, enquanto a maioria dos tribunais definiu o mercado relevante como o de publicidade em buscas online, existem boas razões para que ele seja maior do que isso, podendo abarcar desde toda a publicidade pela internet até toda a publicidade de modo geral. Outras dificuldades apontadas nesta definição são (i) a complexidade que existe na relação entre os resultados orgânicos ${ }^{23}$ e patrocinados, uma vez que as empresas considerarão a possibilidade de apenas investir para melhorar o seu ranking na busca orgânica e (ii) a competição com mecanismos de busca verticais, como os consumidores que buscam diretamente no

\footnotetext{
${ }^{21}$ Fonte: relatórios da consultoria Gartner.

${ }^{22}$ MANNE, Geoffrey; WRIGHT, Joshua. Google and the Limits of Antitrust: The Case Against the Case Against Google. Harvard Journal of Law and Public Policy, v. 34, n. 1, 2011.

23 São os links não patrocinados que aparecem como resultado da busca ao se buscar um termo, listados a partir da relevância atribuída pelo algoritmo.
} 
Ebay ou na Amazon, que gera o risco constante de perda abrupta de mercado do Google.

Em segundo lugar, o caso do Google mostra como auferir a existência de efeitos de rede pode ser difícil na Nova Economia. ${ }^{24}$ Enquanto no caso Microsoft os efeitos de rede indiretos foram essenciais para a caracterização do poder de mercado, no caso Google é difícil dizer que esses efeitos existam da mesma forma. Afinal, os efeitos não parecem ser recíprocos nas pontas no mercado, mas unidirecionais, visto que, apesar de o maior número de usuários agregar valor à plataforma para os anunciantes, os usuários não ganham valor na utilização da plataforma se houver mais anunciantes. Assim, a plataforma de buscas gera efeitos de rede indiretos apenas do lado dos anunciantes, que pagam por esses efeitos nos custos de publicidade, atenuando preocupações com externalidades, mas não do lado dos consumidores. Quanto aos efeitos de rede diretos, muitos apontam que o Google alcançou sua posição favorecida no mercado com base na melhora de seu algoritmo por conta da maior base inicial de usuários. Porém, outros autores apontam que isso não é tão claro assim, uma vez que o Google, quando tinha uma base de usuários semelhante ao que o Bing tem hoje, já tinha um algoritmo de pesquisa semelhante ao atual, e que o levava a conseguir cada vez mais usuários. ${ }^{25}$

No Brasil ${ }^{26}$ e na Europa, ${ }^{27}$ houve investigações de prática de conduta exclusionária por parte do Google, que estaria prejudicando o negócio de sites de comparação de preço, como o Buscapé, em favor do seu serviço Google Shopping. O Google estaria, segundo as investigações, utilizando o seu poder de mercado no setor de buscas para favorecer o seu serviço de comparação de preços, por meio de vieses nas buscas orgânicas e por meio da preferência pelos resultados do seu serviço, que teriam espaço privilegiado nas buscas e só eles mostrariam fotos dos produtos comparados. ${ }^{28}$ No caso, foram utilizados conceitos tradicionais do direito da concorrência para tratar do setor.

Todavia, é preciso ter atenção nesse tipo de caso. Isso porque a verificação do poder de mercado na Nova Economia não é necessariamente igual aos mercados mais estabelecidos, porque se trata de um contexto dinâmico de inovações constantes. Investe-se em inovação tecnológica com o objetivo de criar novas plataformas e competir por novos mercados, que podem ser substituídos em pouco tempo. Nesse sentido, a intervenção antitruste da maneira tradicional pode vir a causar efeitos inibidores nessa inovação (chilling effect), minando a perspectiva de ganhos dos consumidores. Argumentam alguns autores, assim, que of framework do custo dos erros seria uma boa forma de garantir a parcimônia na Nova Economia. ${ }^{29}$ Esse framework,

24 Ver YOO, Christopher; SPULBER, Daniel. Antitrust, the Internet, and the Economics of Networks. Upenn Faculty Scholarship Paper 568, 2013.

${ }^{25}$ Ver MANNE e WRIGHT (2011), op. cit., p. 42 e ss.

${ }^{26}$ Procedimento Administrativo nº 08012.010483/2011-94.

27 Caso AT.39740.

28 Ver despacho da Superintendência-Geral de 10/10/13 no PA no 08012.010483/2011-94.

${ }^{29}$ MANNE, Geoffrey; WRIGHT, Joshua. Innovation and the Limits of Antitrust. Journal of Competition Law \& Economics, v. 6, n. 1, 2010.

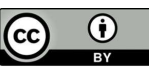


inicialmente proposto por Frank Easterbrook, ${ }^{30}$ parte das premissas (i) de que o custo dos falsos positivos na defesa da concorrência é potencialmente mais alto do que dos falsos negativos, porque os mecanismos de autocorreção do próprio mercado mitigam os primeiros, mas não evitam as distorções causadas pelos últimos, e (ii) de que erros de ambos os tipos são inevitáveis. A inovação criaria oportunidade para erros na análise antitruste por duas razões: primeiro, porque se tratam de novos produtos, plataformas, e práticas negociais, sobre as quais há poucas informações; segundo, e mais importante, porque, quando se trata de inovações disruptivas, tem-se mais a perder do que em intervenções em setores tradicionais, visto que se perdem grandes benefícios em prol dos consumidores.

Como parece claro, a perspectiva tradicional da defesa da concorrência merece ser rediscutida. Nas linhas anteriores, mostrei que existem propostas relevantes de promover tal rediscussão, como o foco em pesquisas sobre os custos dos erros e sobre os riscos da intervenção antitruste. Há, também, um caminho de pesquisa menos óbvio, que é a análise de como os demais papeis vistos nesse artigo interage com a própria rediscussão do papel tradicional do direito da concorrência: por exemplo, o possível desenvolvimento de uma política estatal de intervenção que busca promover a inovação tecnológica pela intervenção antitruste, alterando os padrões de intervenção e os quadros de análise com um viés instrumental do direito da concorrência.

\section{ConCLUSÃo}

Busquei evidenciar os desafios de parte da agenda de pesquisa que floresce no Brasil à medida que o direito da concorrência se aproxima de outras disciplinas e se torna mais relevante no cenário jurídico brasileiro. Mostrei como as interações entre as políticas de intervenção estatal potencializam o campo de estudo do acadêmico da área. Mas os desafios não param por aí. As interseções com a economia possuem diversas outras nuances que não foram discutidas aqui, e as interações com o direito não se limitam à regulação, podendo abranger temas como direito civil e administrativo. $\mathrm{O}$ estudante do direito da concorrência nos próximos anos precisará levar em conta as diversas perspectivas do tema e evoluir constantemente para traçar discussões que tenham impacto em uma área tão dinâmica e interdisciplinar.

${ }^{30}$ EASTERBROOK, Frank. Limits of Antitrust. Texas Law Review, v. 63, n. 1, 1984. 